\title{
Mid-latitude plasma bubbles over China and adjacent areas during a magnetic storm on 08 September 2017
}

Ercha Aa, ${ }^{1,3}$ Wengeng Huang, ${ }^{1}$ Siqing Liu, ${ }^{1,2}$ Aaron Ridley, ${ }^{3}$ Shasha Zou, ${ }^{3}$

Liqin Shi, ${ }^{1,2}$ Yanhong Chen, ${ }^{1}$ Hua Shen, ${ }^{1}$ Tianjiao Yuan, ${ }^{1}$ Jianyong Li, ${ }^{4}$ and

Tan Wang ${ }^{4}$

Correspondence to: E. Aa (aercha@nssc.ac.cn)

${ }^{1}$ National Space Science Center, Chinese

Academy of Sciences, Beijing, China.

${ }^{2}$ University of Chinese Academy of

Sciences, Beijing, China.

${ }^{3}$ Department of Climate and Space

Sciences and Engineering, University of

Michigan, Ann Arbor, USA.

${ }^{4}$ National Earthquake Infrastructure

Service, Beijing, China.

This is the author manuscript accepted for publication and has undergone full peer review but has not been through the copyediting, typesetting, pagination and proofreading process, which may lead to differences between this version and the Version of Record. Please cite this article as doi: 10.1002/2017SW001776 
${ }_{3}$ Abstract. This paper presents observations of post-sunset super plasma 4 bubbles over China and adjacent areas during the second main phase of a 5 storm on 08 Sep 2017. The signatures of the plasma bubbles can be seen or deduced from: 1) deep field-aligned total electron content (TEC) depletions embedded in regional ionospheric maps derived from dense Global Navigation Satellite System (GNSS) networks; 2) significant equatorial and midlatitudinal plasma bite-outs in electron density measurements onboard Swarm satellites; 3) enhancements of ionosonde virtual height and scintillation in local evening associated with strong southward interplanetary magnetic field (IMF). The bubbles/depletions covered a broad area mainly within $20^{\circ}-45^{\circ} \mathrm{N}$ and $80^{\circ}-110^{\circ} \mathrm{E}$ with bifurcated structures and persisted for nearly 5 hours ( $\sim 13-18 \mathrm{UT})$. One prominent feature is that the bubbles extended remarkably along the magnetic field lines in the form of depleted flux tubes, reaching up to mid-latitude of around $50^{\circ} \mathrm{N}$ (MLAT: $45.5^{\circ} \mathrm{N}$ ) that maps to an altitude of $6600 \mathrm{~km}$ over the magnetic equator. The maximum upward drift speed of the bubbles over the magnetic equator was about $700 \mathrm{~m} / \mathrm{s}$, and gradually decreased with altitude and time. The possible triggering mechanism of the plasma bubbles was estimated to be storm-time eastward prompt penetration electric field (PPEF), while the traveling ionospheric disturbance (TID) could play a role in facilitating the latitudinal extension of the depletions. 


\section{Introduction}


$\mathrm{X}-4$

AA ET AL: MID-LATITUDE PLASMA BUBBLES OVER CHINA

45

February 28, 2018, 2:46pm 
71

\section{Data Description}

Measurements from multiple instruments were analyzed to study the characteristics of plasma bubbles under the influence of the geomagnetic storm on 08 Sep 2017. The solar

\section{${ }^{3}$}

wind and geomagnetic conditions during the storm are described in Figure 1 by using solar wind speed, interplanetary magnetic field (IMF) $B_{z}$ component, interplanetary electric field (IEF) $E_{y}$ component, the longitudinal asymmetric index (ASY-H) that represents the auroral activity, and the symmetric index (SYM-H) as the high-resolution Dst index.

The most important information about plasma bubbles are provided by the TEC data 88

February 28, 2018, 2:46pm D R A F T 
$\mathrm{X}-6$

AA ET AL: MID-LATITUDE PLASMA BUBBLES OVER CHINA

90

93

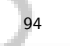

95

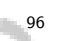

\section{Observational Results}

During the time periods of 07-08 Sep 2017, two coronal mass ejections (CME) passed

\section{.}


Figure 1f shows the corresponding variation of ionospheric virtual height (h'F) over a low latitude station Sanya $\left(18.3^{\circ} \mathrm{N}, 109.4^{\circ} \mathrm{E}\right.$, dip angle: $\left.11.3^{\circ}\right)$. The local dusk to dawn intervals of the station on 08 Sep are marked by shaded areas. Figure $1 \mathrm{f}$ shows that compared with the previous evening, the h'F of Sanya station exhibited a considerable post-sunset increase at around 12:45 UT on 08 Sep, which was consistent with the pronounced increase (decrease) of IEF $E_{y}(\mathrm{SYM}-\mathrm{H})$. These near simultaneous enhancements of h'F and IEF $E_{y}$ indicate that there was a prompt penetration of eastward electric field into middle and low latitude regions at local dusk hours on $08 \mathrm{Sep}$, which added onto the normal post-sunset PRE of zonal electric field, caused larger upward plasma drifts, and generated conditions favorable for the formation of plasma bubbles. Figures $1 \mathrm{~g}$ and $1 \mathrm{~h}$ show the measurements of L-band amplitude scintillations index S4 from GPS/Beidou satellites in the adjacent stations: Kunming $\left(24.2^{\circ} \mathrm{N}, 103.4^{\circ} \mathrm{E}\right.$, dip angle: $\left.17.7^{\circ}\right)$ and Guangzhou $\left(23.2^{\circ} \mathrm{N}, 113.3^{\circ} \mathrm{E}\right.$, dip angle: $\left.16.7^{\circ}\right)$. Weak to moderate scintillations started from around 11:45-12:00 UT on 08 Sep, illustrating the possible generation of plasma irregularities/bubbles induced by the geomagnetic storm.

TEC data can be used to further confirm the existence of plasma bubbles. Figures 2 and 3 show a series of gridded vertical TEC maps over China and adjacent areas at 15 min intervals during 12:45-17:00 UT on 08 Sep 2017. An elevation cutoff of $30^{\circ}$ was used to avoid multi-paths effects. The resolution of the map is $1^{\circ} \times 1^{\circ}$ and was generated by selecting the median of all available measurements in each bin as the estimated grid value, with no interpolation being applied. The signatures of the plasma bubbles appeared in the form of TEC depletions embedded in the maps mainly within $20^{\circ}-45^{\circ} \mathrm{N}$ and $80^{\circ}$ $110^{\circ} \mathrm{E}$, which originated from the equatorial latitudes and then expanded northwestward 
Figures $6 \mathrm{a}-6 \mathrm{~g}$ show the temporal variation of ionospheric pierce points (IPP) vertical TEC at seven stations between 10-16 UT on 08 Sep 2017 for PRNs 10, 18, 21, and 24. The locations of these stations are shown in Figure 2i, which were selected to be evenly distributed along the latitudinal extension of the irregularities as much as possible. The color-bar represents the geographic latitudes of IPP, indicating that TEC depletions can be observed between $15^{\circ} \mathrm{N}$ to $50^{\circ} \mathrm{N}$. Figures $6 \mathrm{~h}-6 \mathrm{n}$ show the associated de-trended TEC results to better illustrate the plasma depletion. The de-trended TEC was calculated by subtracting the 1-hour moving average value of original TEC data. The inclined red thick line marks the trends of the negative wavefront. This can be used to calculate the horizontal phase speed of the depletion, which is estimated to be as much as $\sim 800 \mathrm{~m} / \mathrm{s}$ with roughly a northwestward direction. Considering the previous analysis of Figures 2 and 4, the rate of latitudinal extension of the depletion/irregularities traces in TEC and ROTI maps can be used to estimate the vertical drift speed of equatorial plasma bubbles. The scintillation started at around 1145 UT at Kunming station (MLAT: $17.7^{\circ}$ ), which corresponded to $\sim 650 \mathrm{~km}$ altitude over magnetic equator; while the highest latitude reached by the TEC/ROTI at $\sim 1315 \mathrm{UT}$ is $45^{\circ} \mathrm{N}$ (MLAT: $40.5^{\circ}$ ), which corresponded to $\sim 4600 \mathrm{~km}$ altitude over magnetic equator. It can be estimated that the upward drift speed of plasma bubbles over the magnetic equator was $\sim 700 \mathrm{~m} / \mathrm{s}$ at around 13:15 UT and gradually decreased with increasing altitude and time.

Figure 7 shows satellite passes and the corresponding measurements of electron density from the Swarm constellation from 12 UT to 18 UT on 08 Sep 2017. Swarm A and Swarm C flew at an altitude of $440-460 \mathrm{~km}$. They have nearby longitudes that approximately located in $\sim 10 \mathrm{LT}$ (ascending) and $\sim 22 \mathrm{LT}$ (descending) sectors. The geographic maps 
$\mathrm{X}-10$

AA ET AL: MID-LATITUDE PLASMA BUBBLES OVER CHINA

with different satellite orbit paths between $60^{\circ} \mathrm{N}-60^{\circ} \mathrm{S}$ are shown in Figures $7 \mathrm{a}$ and $7 \mathrm{~b}$ for Swarm A and C, respectively. The right panels show the variation of in situ electron density (Ne) with respect to latitude along these paths. Swarm B is not shown here since its did not pass over China and adjacent sectors in the local post-sunset hours during this storm period. Swarm A measured no signatures of equatorial plasma bubbles in paths \#1 $\left(147^{\circ} \mathrm{E}\right)$ and $\# 2\left(123^{\circ} \mathrm{E}\right)$, though obvious plasma depletions were detected at $\sim 40^{\circ} \mathrm{S}$. However, the satellite in path $\# 3\left(100^{\circ} \mathrm{E}\right)$ measured a wide and drastic density depletion near the equator as low as $2 \times 10^{3} \mathrm{el} / \mathrm{cm}^{2}$, which was 2-3 orders of magnitude lower than normal Ne conditions. The coverage of major depletion was between $10^{\circ} \mathrm{S}$ and $20^{\circ} \mathrm{N}$ with several minor negative spikes distributed in the middle latitudes of both hemispheres, which can be clearly distinguished from the main ionospheric mid-latitude trough at around $50^{\circ}-60^{\circ}$. Similar observations were made by Swarm $\mathrm{C}$ as shown in Figure 7b. The TEC results that coincide with path \#3 (\#8) at 15:15 UT and with path \#4 (\#9) at 16:45 UT are also superimposed on Figures 7a and 7b, respectively. Recall from Figures $3 \mathrm{~b}$ and $3 \mathrm{~h}$ that the same paths of Swarm were also shown there with four intersections between satellite paths and TEC depletions being marked. It can be seen that these intersections (X1-X4) correspond nicely to the mid-latitude bite-outs in the plasma profiles. This demonstrates that the latitudinal elongated plasma depletion was mainly associated with plasma bubbles, though another factor that the Swarm orbit being below the $\mathrm{F}$ layer peak might also play a role in it. This bubble-associated extension of depletion was also reported by several studies [e.g. Basu et al., 2001; Kil et al., 2006; Huang et al., 2007; Cherniak and Zakharenkova, 2016]. These studies indicate that the plasma bubbles can be lifted to higher altitudes with depletions being extended along the 
$(0$

\section{Discussion}

Firstly, the results presented in the previous section indicate that there were significant equatorial plasma bubbles over China and adjacent sectors in local dusk hours on 08 Sep 2017, which were associated with strong PPEF as can be deduced from the simultaneously drastic change of IMF $\mathrm{B}_{z}$, IEF, SYM-H, and ionosphere virtual height during the second main phase of the storm. It is generally assumed that PPEF is eastward (westward) during daytime through dusk sectors (midnight to dawn sectors), and can penetrate nearly instantly to low latitudes and has a relatively short duration $(\sim 1-2 \mathrm{~h})$; On the other hand, DDEF is westward (eastward) during daytime (nighttime), and the build-up time of the DDEF after storm onset is comparatively long $(>3 \mathrm{~h})$ such that it may take up to 1-2 days before the equatorial ionospheric response can be fully observed [Fejer, 1991; Li et al., 2009b; Horvath and Lovell, 2013; Tulasi Ram et al., 2015]. Huang [2008] and Huang et al. [2010] also pointed out that the PPEF is approximately proportional to the IEF during the storm main phase. Recall from Figures $1 \mathrm{c}$ and $1 \mathrm{f}$ that the IEF $\mathrm{E}_{y}$ drastically increased from $-6.5 \mathrm{mV} / \mathrm{m}$ (11:35 UT) to $13.76 \mathrm{mV} / \mathrm{m}$ (11:58 UT) on 08 Sep 2017, and h'F at Sanya station exhibited considerable increase simultaneously. This eastward IEF corresponds to eastward PPEF. In addition, the evolution of TEC depletion and ROTI fluctuation were 
also consistent with the variation of IMF $B_{z}$, IEF $E_{y}$, and SYM-H, which collectively show that it was the PPEF that drove the development of equatorial plasma bubbles.

Secondly, recent studies have shown that the PPEF can persist with considerably longer durations of $\sim 8$-10h if the IMF $B_{z}$ is sustained southward for prolonged periods [Huang et al., 2005; Huang, 2008]. Recall from Figure 1b that during the second main phase of the storm on 08 Sep, the IMF $B_{z}$ suddenly dropped to $-17.4 \mathrm{nT}$ at 11:55 UT and remained southward for several hours, which suggests that there was a continuous PPEF since 12:00 UT. Moreover, some studies found that the PPEF could be eastward even at 22-23 LT [e.g. Fejer et al., 2008; Chakrabarty et al., 2015], which may be the case for this event that is evidenced in Figure 7, which shows that significant equatorial plasma depletions were measured along path \#3 of Swarm A and path \#8 of Swarm C at around 15.5 UT ( 22 LT). It appears therefore that a possible extension of the upward vertical drift towards longer duration due to the consistent PPEF might have contributed to the bubble growth rate.

Thirdly, one important aspect regarding the plots from Figures 2 to 5 is that the TEC irregularity traces were displaced westward in the successive plots and further the declination of the traces with the N-S meridian increases as time increases. These characteristics suggest that the irregularity structures drift westward with velocity increasing with increasing latitude. Since the observation of bubbles was preceded by the first main phase of storm event about 12 hours earlier, there is possibility of atmospheric gravity waves (AGWs) that generated in auroral zone and propagated equatorward, which could create traveling ionospheric disturbance (TID) that acted on the field-aligned bubble traces to shape such a latitude dependent drift. 


\section{Conclusion}


was as much as $700 \mathrm{~m} / \mathrm{s}$ at around $13 \mathrm{UT}$ and gradually decreased with altitude and time. This study provides useful evidence in demonstrating the link between equatorial and mid-latitude electrodynamics. The observed plasma depletions persisted for several hours and expanded northwestward along the magnetic field lines to mid-latitude regions, which could be attributed to both equatorial plasma bubbles and medium-scale TID. The highest latitude where the depletions reached was around $50^{\circ} \mathrm{N}$ (MLAT: $45.5^{\circ} \mathrm{N}$ ), which suggest that the plasma bubbles might reach an apex height of $6600 \mathrm{~km}$ over the magnetic equator. However, this estimation is likely to be an upper limit since the transition of depletion signature from one of plasma bubbles to that of TID is not well defined, which need to be studied in the future.

Acknowledgments. This work is sponsored by the National Key R\&D Program of China (2016YFB0501503), National Science Foundation of China (41404125, 41674183), and Youth Innovation Promotion Association of Chinese Academy of Sciences. The CMONOC data are available from the National Earthquake Infrastructure Service of China after registration approval via email at (cmonoc@seis.ac.cn). The IGS data are acquired from NASA Earth Science Data Systems that archived and distributed by the Crustal Dynamics Data Information System (CDDIS). The IMF $B_{z}$ and IEF $E_{y}$ data are obtained from the NASA Goddard Space Flight Center Omniweb Interface (https://omniweb.gsfc.nasa.gov). ASY-H and SYM-H indices are obtained from the World Data Center for Geomagnetism, Kyoto University (wdc.kugi.kyotou.ac.jp). We greatly appreciate the University of Massachusetts Lowell for providing ionosonde data from the DIDB database of Global Ionospheric Radio Observatory (http://spase.info/SMWG/Observatory/GIRO). 


\section{References}

Aa, E., W. Huang, S. Liu, L. Shi, J. Gong, Y. Chen, and H. Shen (2015), A regional ionospheric TEC mapping technique over China and adjacent areas: GNSS data processing and DINEOF analysis, Sci. China Inf. Sci., 58(10), 1-11, doi:10.1007/s11432-015-53992.

Abadi, P., Y. Otsuka, and T. Tsugawa (2015), Effects of pre-reversal enhancement of E $\times$ B drift on the latitudinal extension of plasma bubble in Southeast Asia, Earth, Planets, and Space, 67, 74, doi:10.1186/s40623-015-0246-7.

Abdu, M. A. (2012), Equatorial spread F/plasma bubble irregularities under storm time disturbance electric fields, J. Atmos. Terr. Phys., 75, 44-56, doi: 10.1016/j.jastp.2011.04.024.

Abdu, M. A., J. H. Sastri, J. MacDougall, I. S. Batista, and J. H. A. Sobral (1997), Equatorial disturbance dynamo electric field longitudinal structure and spread F: A case study from GUAR/EITS Campaigns, Geophys. Res. Lett., 24, 1707-1710, doi: 10.1029/97GL01465.

Abdu, M. A., I. S. Batista, H. Takahashi, J. MacDougall, J. H. Sobral, A. F. Medeiros, and N. B. Trivedi (2003), Magnetospheric disturbance induced equatorial plasma bubble development and dynamics: A case study in Brazilian sector, J. Geophys. Res., 108, 1449, doi:10.1029/2002JA009721.

Basu, S., S. Basu, K. M. Groves, H.-C. Yeh, S.-Y. Su, F. J. Rich, P. J. Sultan, and M. J. Keskinen (2001), Response of the equatorial ionosphere in the South Atlantic Region to the Great Magnetic Storm of July 15, 2000, Geophys. Res. Lett., 28, 3577-3580, doi:10.1029/2001GL013259. 
Basu, S., S. Basu, K. M. Groves, E. MacKenzie, M. J. Keskinen, and F. J. Rich (2005), Near-simultaneous plasma structuring in the midlatitude and equatorial ionosphere during magnetic superstorms, Geophys. Res. Lett., 32, L12S05, doi:10.1029/2004GL021678.

Basu, S., S. Basu, F. J. Rich, K. M. Groves, E. MacKenzie, C. Coker, Y. Sahai, P. R. Fagundes, and F. Becker-Guedes (2007), Response of the equatorial ionosphere at dusk to penetration electric fields during intense magnetic storms, J. Geophys. Res., 112, A08308, doi:10.1029/2006JA012192.

Bhattacharyya, A., S. Basu, K. M. Groves, C. E. Valladares, and R. Sheehan (2001), Dynamics of equatorial $\mathrm{F}$ region irregularities from spaced receiver scintillation observations, Geophys. Res. Lett., 28, 119-122, doi:10.1029/2000GL012288.

Carter, B. A., E. Yizengaw, R. Pradipta, J. M. Retterer, K. Groves, C. Valladares, R. Caton, C. Bridgwood, R. Norman, and K. Zhang (2016), Global equatorial plasma bubble occurrence during the 2015 St. Patrick's Day storm, J. Geophys. Res. Space Physics, 121, 894-905, doi:10.1002/2015JA022194.

Chakrabarty, D., D. Rout, R. Sekar, R. Narayanan, G. D. Reeves, T. K. Pant, B. Veenadhari, and K. Shiokawa (2015), Three different types of electric field disturbances affecting equatorial ionosphere during a long-duration prompt penetration event, J. Geophys. Res. Space Physics, 120, 4993-5008, doi:10.1002/2014JA020759.

Cherniak, I., and I. Zakharenkova (2016), First observations of super plasma bubbles in Europe, Geophys. Res. Lett., 43, 11, doi:10.1002/2016GL071421.

Cherniak, I., A. Krankowski, and I. Zakharenkova (2014), Observation of the ionospheric irregularities over the Northern Hemisphere: Methodology and service, Radio Sci., 49, 653-662, doi:10.1002/2014RS005433. 
Farley, D. T., E. Bonelli, B. G. Fejer, and M. F. Larsen (1986), The prereversal enhancement of the zonal electric field in the equatorial ionosphere, J. Geophys. Res., 91, 13,723-13,728, doi:10.1029/JA091iA12p13723.

Fejer, B. G. (1991), Low latitude electrodynamic plasma drifts - A review, J. Atmos. Terr. Phys., 53, 677-693, doi:10.1016/0021-9169(91)90121-M.

Fejer, B. G., L. Scherliess, and E. R. de Paula (1999), Effects of the vertical plasma drift velocity on the generation and evolution of equatorial spread F, J. Geophys. Res., 104, 19,859-19,870, doi:10.1029/1999JA900271.

Fejer, B. G., J. W. Jensen, and S.-Y. Su (2008), Seasonal and longitudinal dependence of equatorial disturbance vertical plasma drifts, Geophys. Res. Lett., 35, L20106, doi: 10.1029/2008GL035584.

Foster, J. C., and F. J. Rich (1998), Prompt midlatitude electric field effects during severe geomagnetic storms, J. Geophys. Res., 103, 26,367-26,372, doi:10.1029/97JA03057.

Horvath, I., and B. C. Lovell (2013), Equatorial westward electrojet impacting equatorial ionization anomaly development during the 6 April 2000 superstorm, J. Geophys. Res., 118, 7398-7409, doi:10.1002/2013JA019311.

Huang, C.-S. (2008), Continuous penetration of the interplanetary electric field to the equatorial ionosphere over eight hours during intense geomagnetic storms, J. Geophys. Res., 113, A11305, doi:10.1029/2008JA013588.

Huang, C.-S., J. C. Foster, and M. C. Kelley (2005), Long-duration penetration of the interplanetary electric field to the low-latitude ionosphere during the main phase of magnetic storms, J. Geophys. Res., 110, A11309, doi:10.1029/2005JA011202.

Huang, C.-S., J. C. Foster, and Y. Sahai (2007), Significant depletions of the ionospheric 
plasma density at middle latitudes: A possible signature of equatorial spread F bubbles near the plasmapause, J. Geophys. Res., 112, A05315, doi:10.1029/2007JA012307.

Huang, C.-S., F. J. Rich, and W. J. Burke (2010), Storm time electric fields in the equatorial ionosphere observed near the dusk meridian, J. Geophys. Res., 115, A08313, doi:10.1029/2009JA015150.

Katamzi-Joseph, Z. T., J. B. Habarulema, and M. Hernández-Pajares (2017), Midlatitude postsunset plasma bubbles observed over europe during intense storms in april 2000 and 2001, Space Weather, 15(9), 1177-1190, doi:10.1002/2017SW001674.

Kelley, M. C., G. Haerendel, H. Kappler, A. Valenzuela, B. B. Balsley, D. A. Carter, W. L. Ecklund, C. W. Carlson, B. Haeusler, and R. Torbert (1976), Evidence for a Rayleigh-Taylor type instability and upwelling of depleted density regions during equatorial spread F, Geophys. Res. Lett., 3, 448-450, doi:10.1029/GL003i008p00448.

Kelley, M. C., J. J. Makela, B. M. Ledvina, and P. M. Kintner (2002), Observations of equatorial spread-F from Haleakala, Hawaii, Geophys. Res. Lett., 29, 2003, doi: 10.1029/2002GL015509.

Kelley, M. C., J. J. Makela, L. J. Paxton, F. Kamalabadi, J. M. Comberiate, and H. Kil (2003), The first coordinated ground- and space-based optical observations of equatorial plasma bubbles, Geophys. Res. Lett., 30, 1766, doi:10.1029/2003GL017301.

Kil, H. (2015), The Morphology of Equatorial Plasma Bubbles - a review, J. Astron. Space Sci., 32, 13-19, doi:10.5140/JASS.2015.32.1.13.

Kil, H., L. J. Paxton, S.-Y. Su, Y. Zhang, and H. Yeh (2006), Characteristics of the storm-induced big bubbles (SIBBs), J. Geophys. Res., 111, A10308, doi: 10.1029/2006JA011743. 
Li, G., B. Ning, B. Zhao, L. Liu, W. Wan, F. Ding, J. S. Xu, J. Y. Liu, and K. Yumoto (2009a), Characterizing the 10 November 2004 storm-time middle-latitude plasma bubble event in Southeast Asia using multi-instrument observations, J. Geophys. Res., 114, A07304, doi:10.1029/2009JA014057.

Li, G., B. Ning, L. Liu, W. Wan, and J. Y. Liu (2009b), Effect of magnetic activity on plasma bubbles over equatorial and low-latitude regions in East Asia, Ann. Geophys., 27, 303-312, doi:10.5194/angeo-27-303-2009.

Ma, G., and T. Maruyama (2006), A super bubble detected by dense GPS network at east Asian longitudes, Geophys. Res. Lett., 33, L21103, doi:10.1029/2006GL027512.

Makela, J. J., and M. C. Kelley (2003), Field-aligned 777.4-nm composite airglow images of equatorial plasma depletions, Geophys. Res. Lett., 30, 1442, doi:10.1029/2003GL017106.

Mendillo, M., E. Zesta, S. Shodhan, P. J. Sultan, R. Doe, Y. Sahai, and J. Baumgardner (2005), Observations and modeling of the coupled latitude-altitude patterns of equatorial plasma depletions, J. Geophys. Res., 110, A09303, doi:10.1029/2005JA011157.

Mendillo, M., D. Hickey, C. Martinis, J. Wroten, and J. Baumgardner (2018), Space weather nowcasting for area-denied locations: Testing all-sky imaging applications at geomagnetic conjugate points, Space Weather, 16(1), 47-56, doi:10.1002/2017SW001741.

Ott, E. (1978), Theory of Rayleigh-Taylor bubbles in the equatorial ionosphere, J. Geophys. Res., 83, 2066-2070, doi:10.1029/JA083iA05p02066.

Perkins, F. (1973), Spread F and ionospheric currents, J. Geophys. Res., 78, 218-226, doi:10.1029/JA078i001p00218.

Pi, X., A. J. Mannucci, U. J. Lindqwister, and C. M. Ho (1997), Monitoring of global ionospheric irregularities using the Worldwide GPS Network, Geophys. Res. Lett., 24, 

2283-2286, doi:10.1029/97GL02273.

Ramsingh, S. Sripathi, S. Sreekumar, S. Banola, K. Emperumal, P. Tiwari, and B. S. Kumar (2015), Low-latitude ionosphere response to super geomagnetic storm of 17/18 March 2015: Results from a chain of ground-based observations over Indian sector, J. Geophys. Res. Space Physics, 120, 10, doi:10.1002/2015JA021509.

Retterer, J. M., and P. Roddy (2014), Faith in a seed: on the origins of equatorial plasma bubbles, Ann. Geophys., 32, 485-498, doi:10.5194/angeo-32-485-2014.

Scherliess, L., and B. G. Fejer (1997), Storm time dependence of equatorial disturbance dynamo zonal electric fields, J. Geophys. Res., 102, 24,037-24,046, doi: 10.1029/97JA02165.

Shiokawa, K., Y. Otsuka, T. Ogawa, N. Balan, K. Igarashi, A. J. Ridley, D. J. Knipp, A. Saito, and K. Yumoto (2002), A large-scale traveling ionospheric disturbance during the magnetic storm of 15 September 1999, J. Geophys. Res., 10\%, 1088, doi: 10.1029/2001JA000245.

Shiokawa, K., C. Ihara, Y. Otsuka, and T. Ogawa (2003), Statistical study of nighttime medium-scale traveling ionospheric disturbances using midlatitude airglow images, $J$. Geophys. Res., 108, 1052, doi:10.1029/2002JA009491.

Tsugawa, T., Y. Otsuka, A. J. Coster, and A. Saito (2007), Medium-scale traveling ionospheric disturbances detected with dense and wide TEC maps over North America, Geophys. Res. Lett., 34, L22101, doi:10.1029/2007GL031663.

Tsunoda, R. T. (1980), Magnetic-field-aligned characteristics of plasma bubbles in the nighttime equatorial ionosphere, J. Atmos. Terr. Phys., 42, 743-752, doi:10.1016/00219169(80)90057-4. 
430

Tsunoda, R. T., R. C. Livingston, J. P. McClure, and W. B. Hanson (1982), Equatorial plasma bubbles - Vertically elongated wedges from the bottomside F layer, J. Geophys. Res., 87, 9171-9180, doi:10.1029/JA087iA11p09171.

Tulasi Ram, S., P. V. S. Rama Rao, D. S. V. V. D. Prasad, K. Niranjan, S. Gopi Krishna, R. Sridharan, and S. Ravindran (2008), Local time dependent response of postsunset ESF during geomagnetic storms, J. Geophys. Res., 113, A07310, doi: 10.1029/2007JA012922.

Tulasi Ram, S., S. Kumar, S.-Y. Su, B. Veenadhari, and S. Ravindran (2015), The influence of Corotating Interaction Region (CIR) driven geomagnetic storms on the development of equatorial plasma bubbles (EPBs) over wide range of longitudes, Adv. Space Res., 55, 535-544, doi:10.1016/j.asr.2014.10.013.

Woodman, R. F., and C. La Hoz (1976), Radar observations of F region equatorial irregularities, J. Geophys. Res., $81(31)$, 5447-5466, doi:10.1029/JA081i031p05447. 


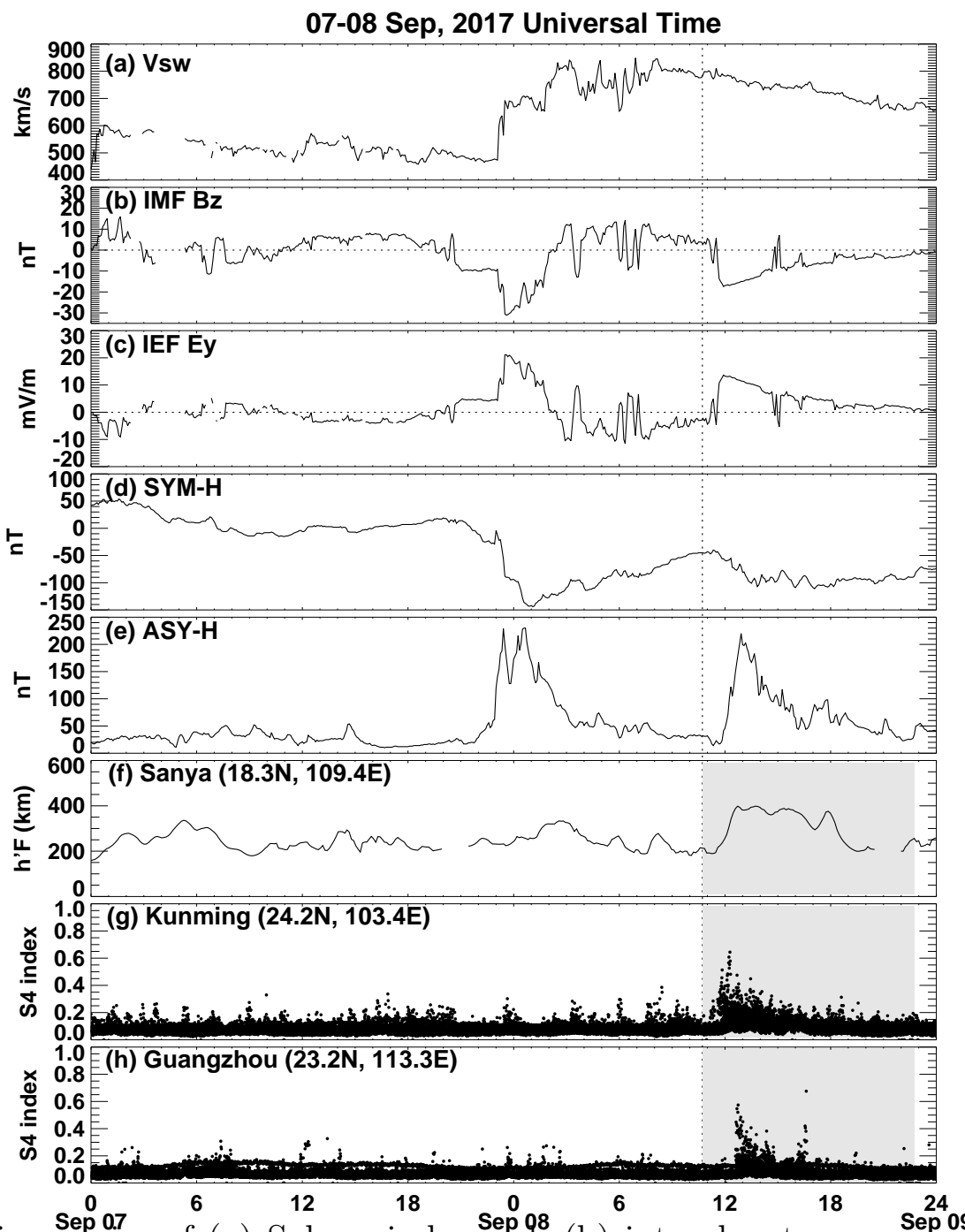

Figure 1. Time Series of (a) Solar wind speed; (b) interplanetary maghetic field (IMF) $\mathrm{B}_{z}$, (c) interplanetary electric field (IEF) $\mathrm{E}_{y}$, (d) SYM-H index, (e) ASY-H index, (f) ionospheric virtual height (h'F) over Sanya, and S4 scintillation index during the period of 07-08 September 2017 for Kunming (g) and Guangzhou (h). The solar wind and IMF data have been shifted to the nose of the Earth's bow shock. The shaded areas represent the local dusk to dawn period at these stations. 
a) 08-SEP-2017 12:45 UT
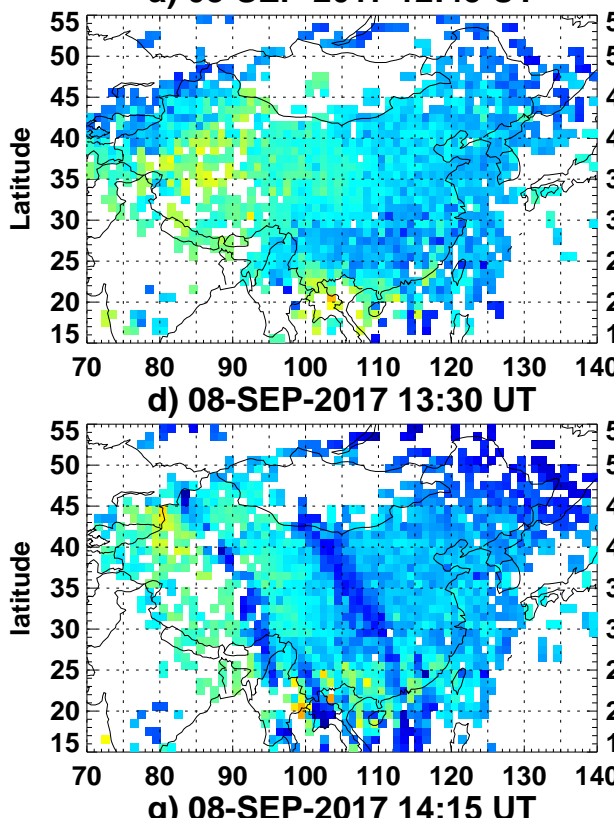

g) 08-SEP-2017 14:15 UT

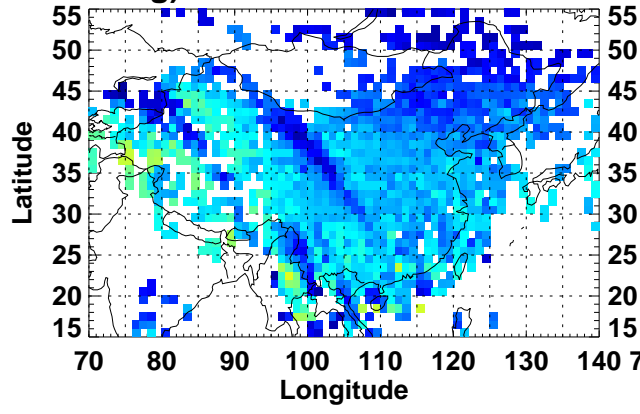

b) 08-SEP-2017 13:00 UT

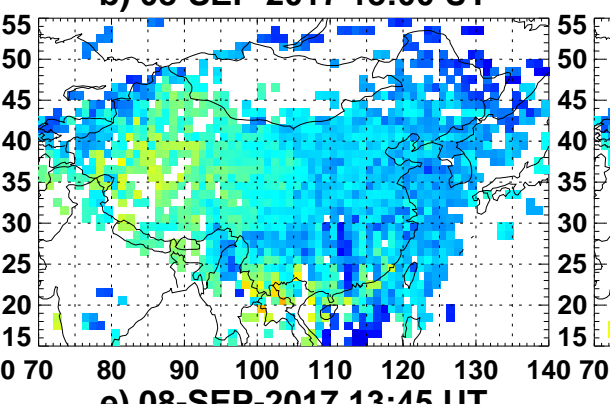

c) 08-SEP-2017 13:15 UT

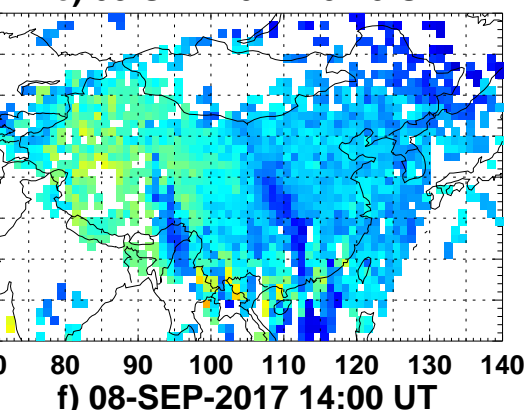

e) 08-SEP-2017 13:45 UT

f) 08-SEP-2017 14:00 UT

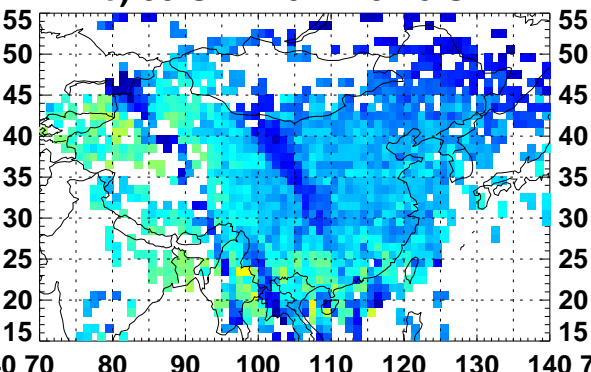

h) 08-SEP-2017 14:30 UT
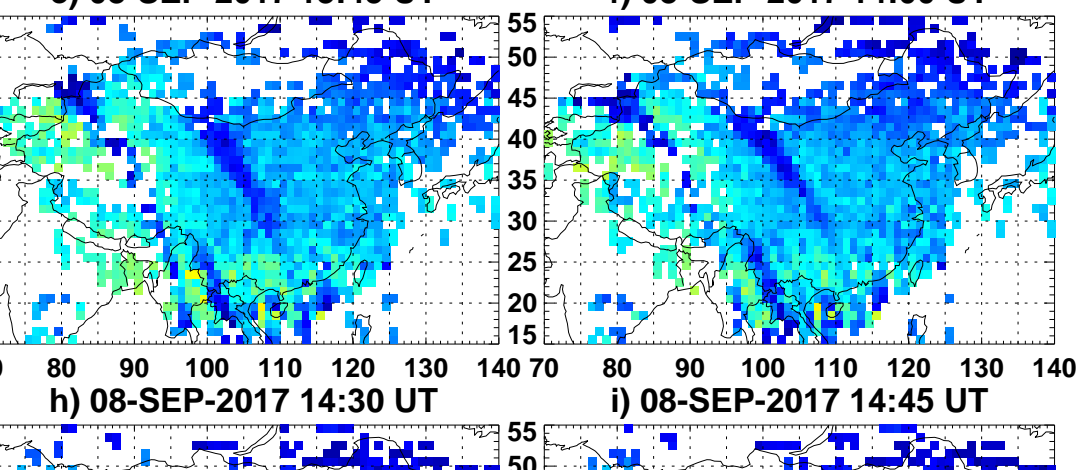

50
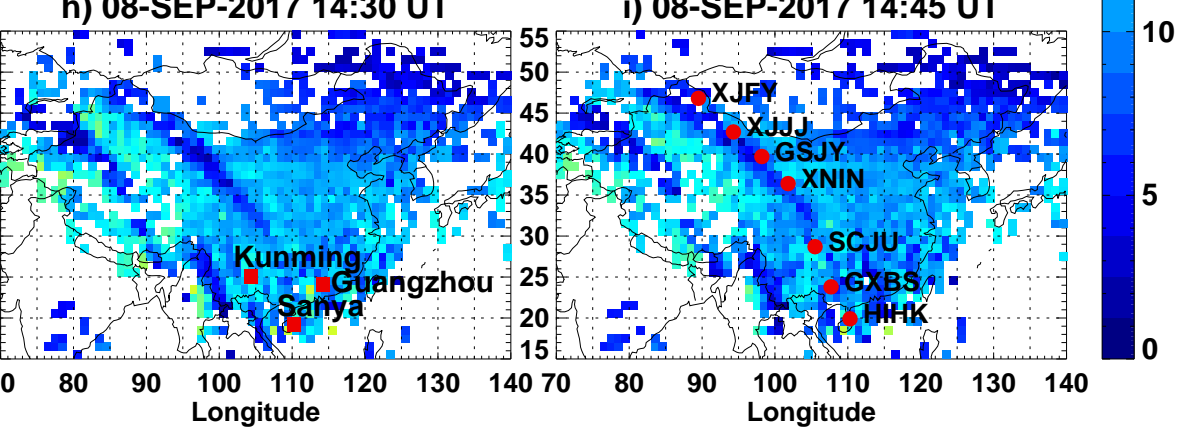

Figure 2. Gridded TEC maps over China and adjacent areas with 15 min interval during 12:45-14:45 UT on 08 September 2017. The distribution of ionosonde/scintillation stations used in current study are shown in Figure 2h. Seven GNSS stations are marked in Figure 2i to track the trace of irregularities. 


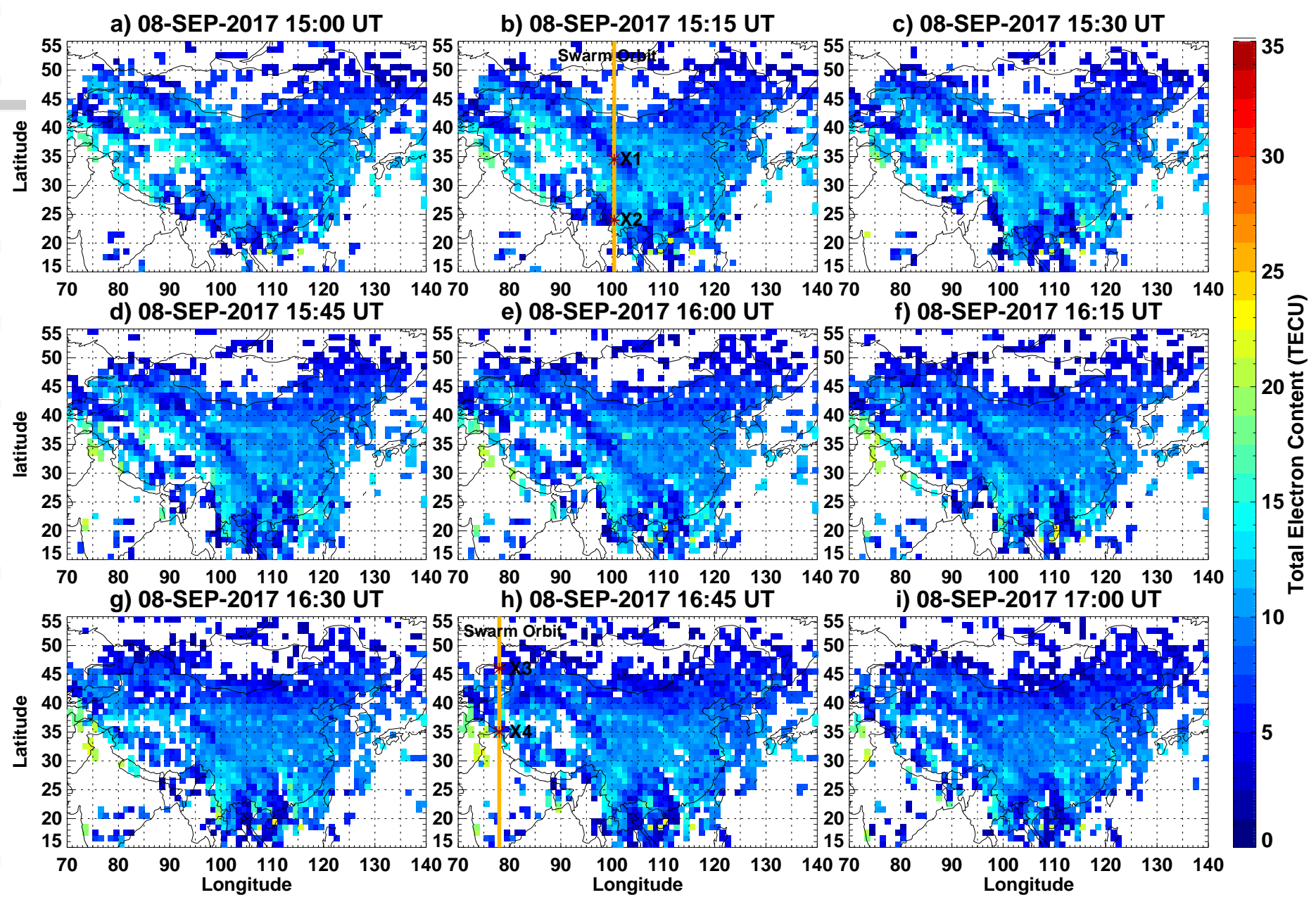

Figure 3. Same as Figure 2, but for time period of 15:00-17:00 UT on 08 September 2017.

The Swarm satellite orbits are superimposed on TEC depletions for Figure $3 \mathrm{~b}$ and $3 \mathrm{~h}$ with four

points of intersection being marked by asterisks. 
a) 08-SEP-2017 12:45 UT

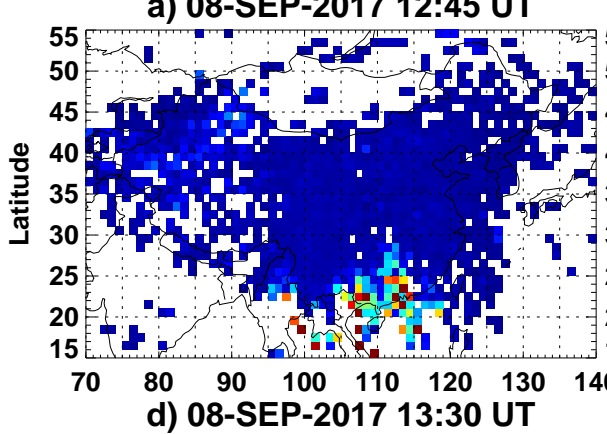

b) 08-SEP-2017 13:00 UT

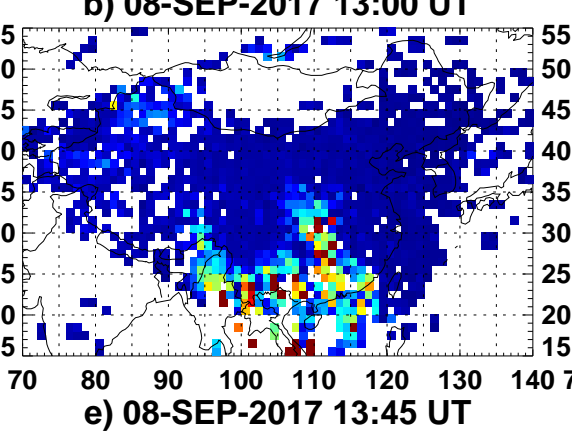

c) 08-SEP-2017 13:15 UT

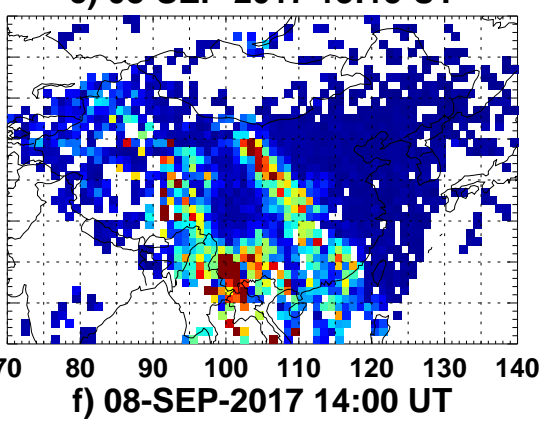

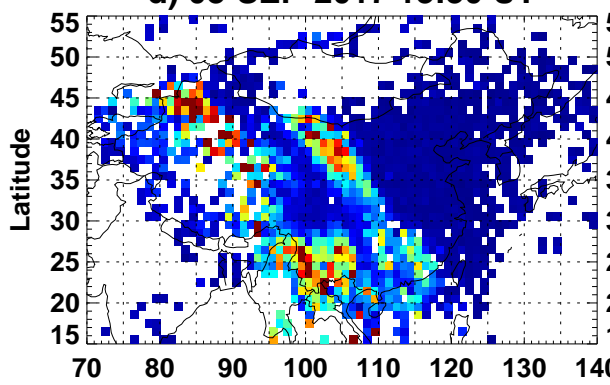

g) 08-SEP-2017 14:15 UT

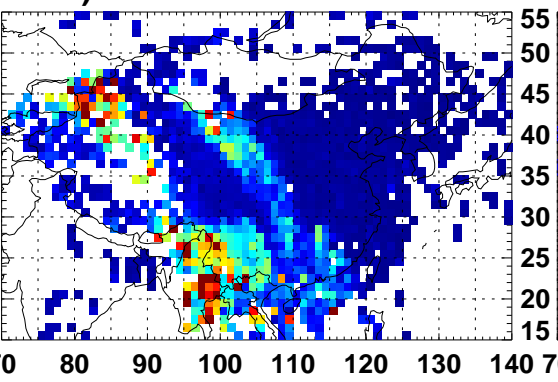

h) 08-SEP-2017 14:30 UT

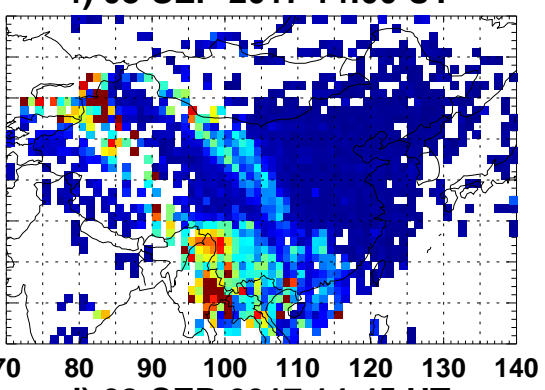

i) 08-SEP-2017 14:45 UT
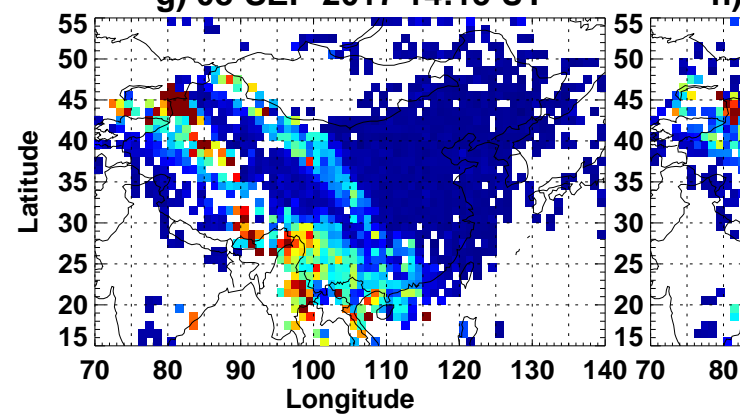

(1)

Figure 4. ROTI maps of ionospheric irregularities over China and adjacent areas with 15 min interval during 12:45-14:45 UT on 08 September 2017. 
a) 08-SEP-2017 15:00 UT

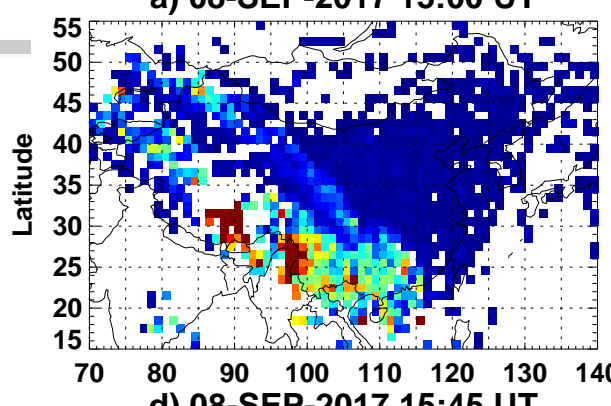

d) 08-SEP-2017 15:45 UT

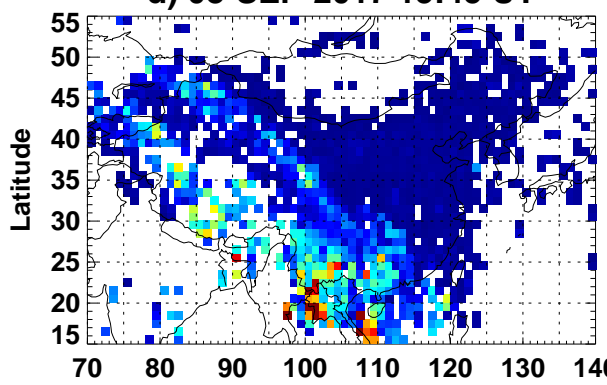

g) 08-SEP-2017 16:30 UT

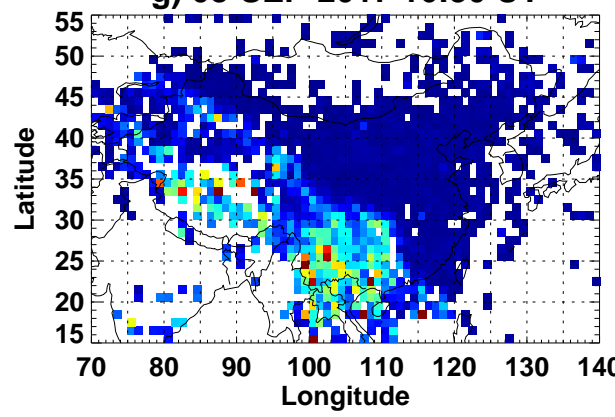

b) 08-SEP-2017 15:15 UT

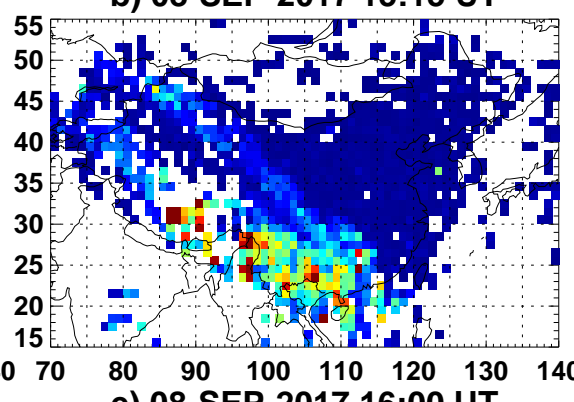

e) 08-SEP-2017 16:00 UT

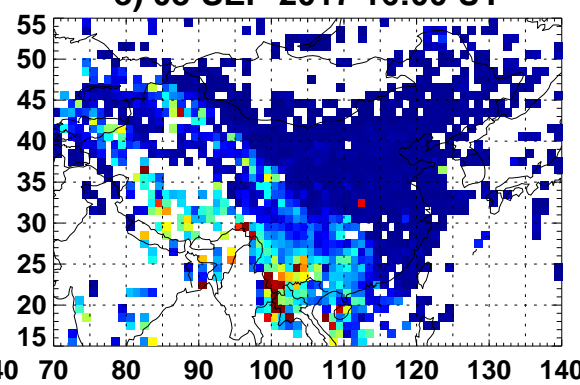

h) 08-SEP-2017 16:45 UT

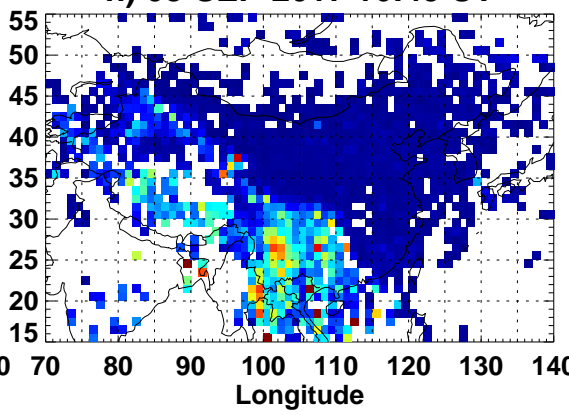

c) 08-SEP-2017 15:30 UT

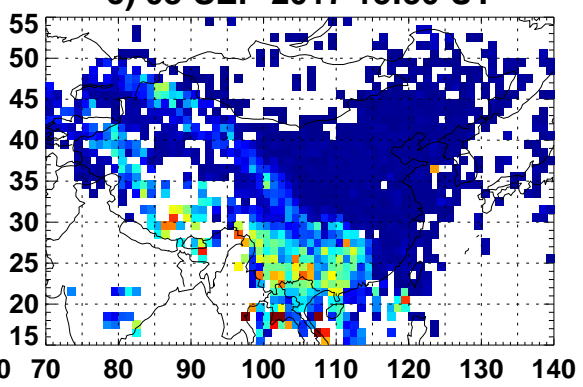

f) 08-SEP-2017 16:15 UT

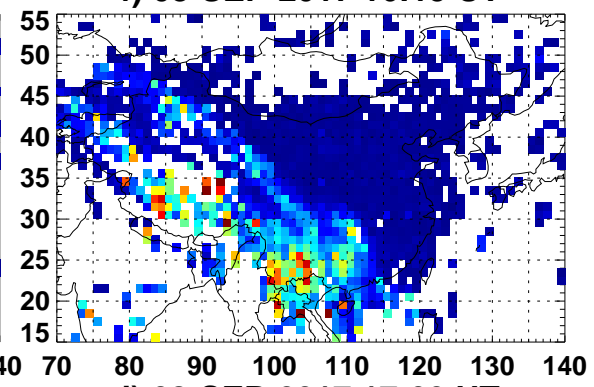

i) 08-SEP-2017 17:00 UT

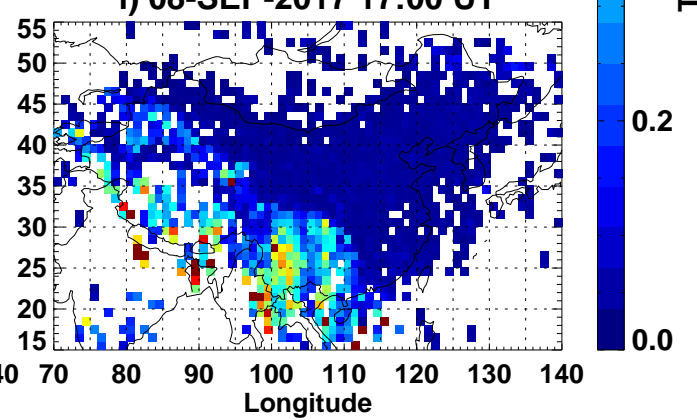

Figure 5. Same as Figure 4, but for time period of 15:00-17:00 UT on 08 September 2017. 

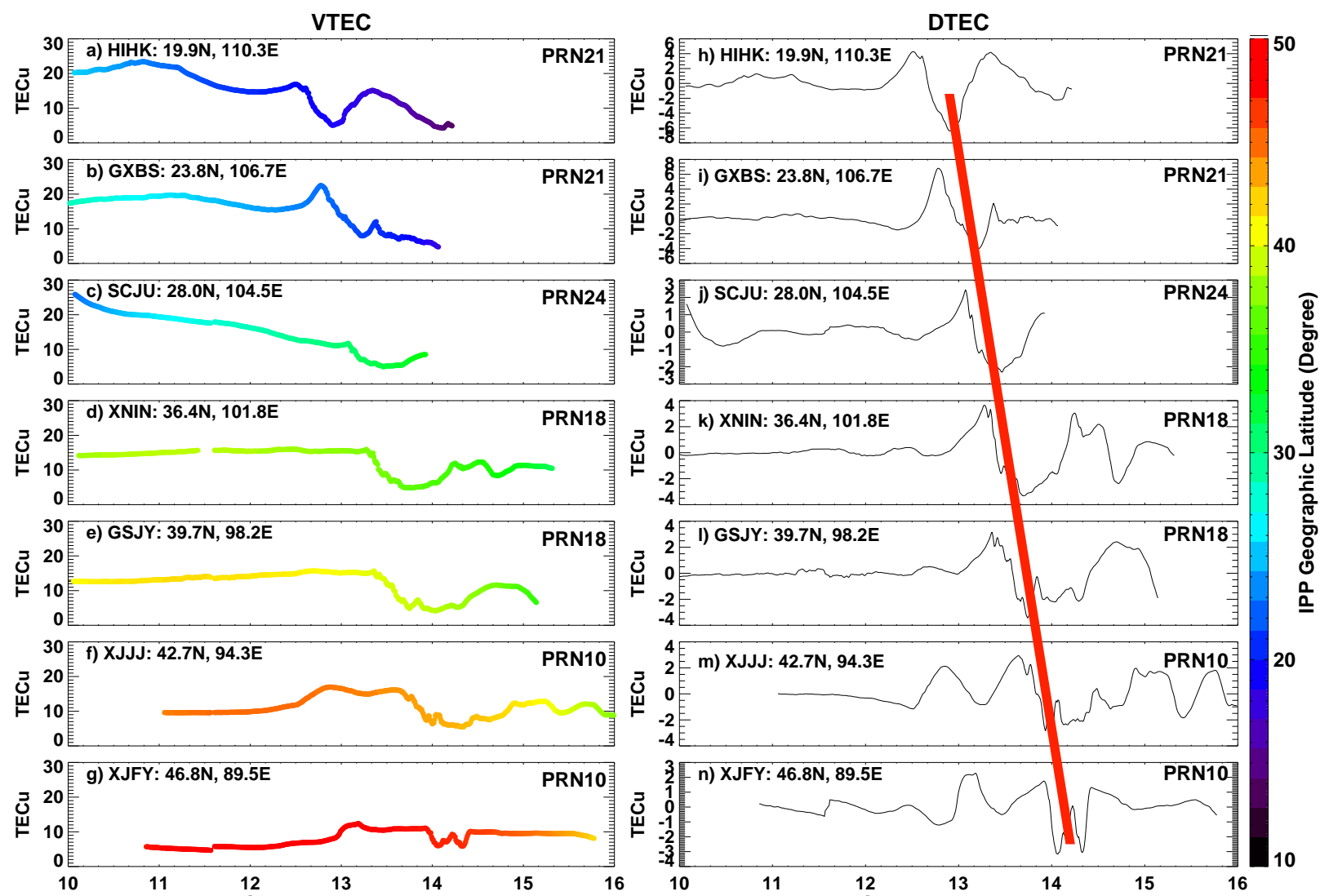

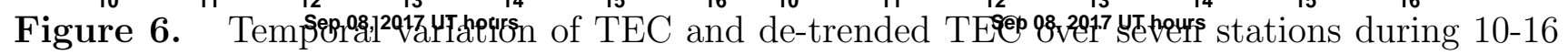
UT on 08 September 2017. The color bar shows the geographic latitude range of the ionospheric pierce points (IPP). The red thick line marks the propagation of the depletions. 
a) Swarm A

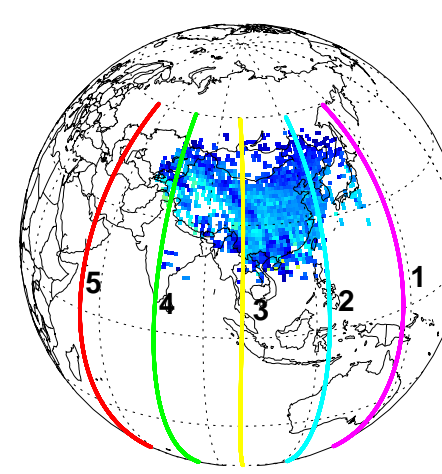

b) Swarm C

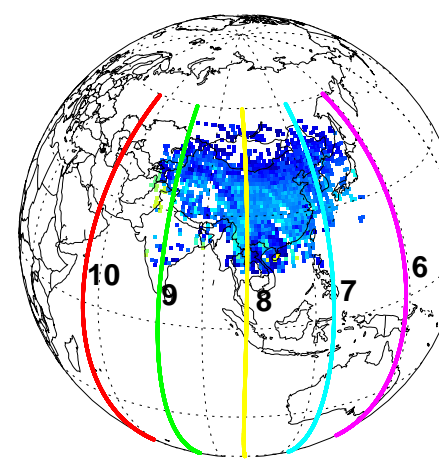

In situ Electron Density (Altitude $=\sim 450 \mathrm{~km}$ )

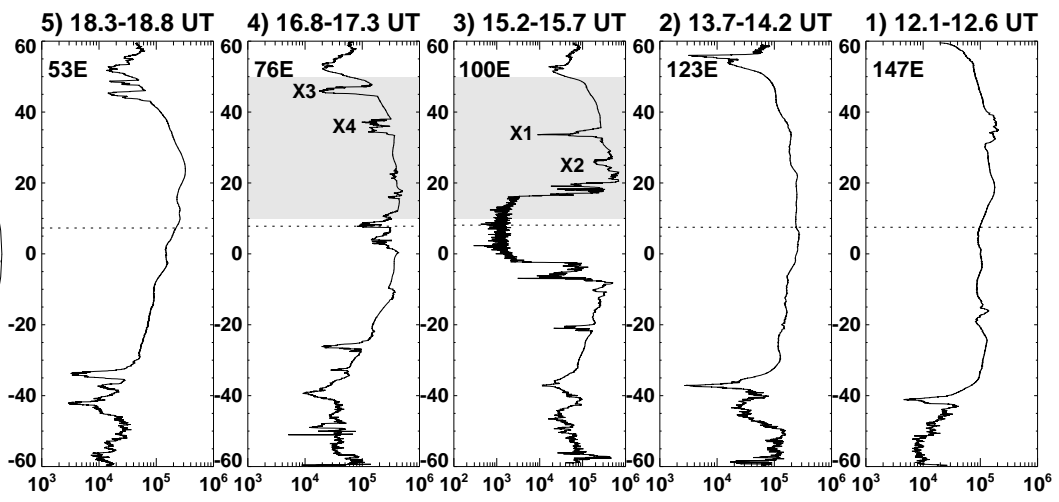

In situ Electron Density (Altitude $=\sim 450 \mathrm{~km}$ )

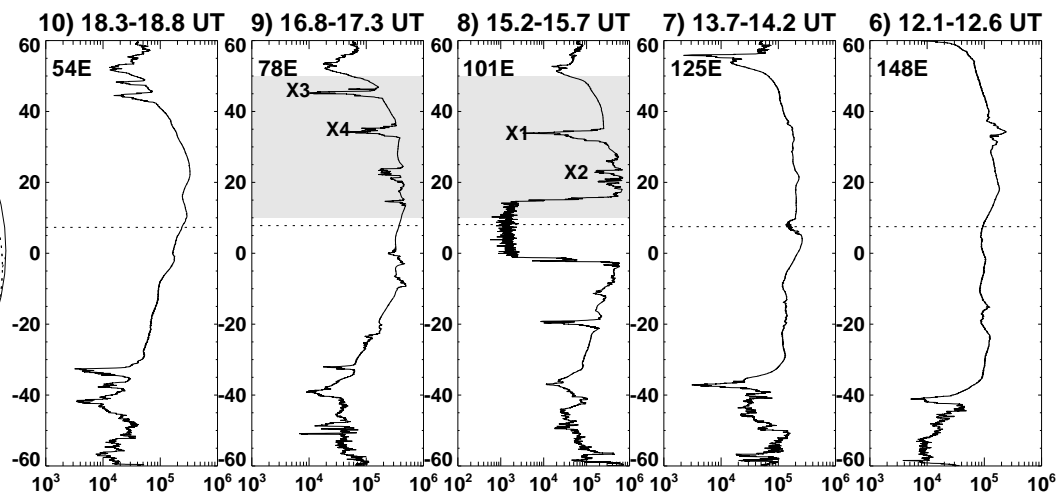

Figure 7. (a) (left) The global map with 5 different satellite orbit paths of Swarm A, with gridded TEC at 15:15 UT being superimposed; (right) variation of in situ electron density as a function of geographic latitudes along these paths. (b) the same as Figure 7a, but for Swarm C satellite with gridded TEC at 16:45 UT being superimposed. The shaded areas represent plasma depletions over China and adjacent regions. Four intersection points X1-X4 that marked in Figure 3b and 3h are also shown here. The magnetic equator is indicated by dotted horizontal lines on the density-latitude profiles. 